\title{
Complex partial status epilepticus associated with cyclosporin A therapy
}

\author{
R E APPLETON,* K FARRELL, $*$ P TEAL, $\dagger$ S A HASHIMOTO, $\dagger$ P K H WONG $\dagger$ \\ From the Division of Neurology, Department of Paediatrics* and Department of Medicine, $\dagger$ University of \\ British Columbia, Vancouver, Canada.
}

SUMMARY Significant neurotoxicity including seizures, encephalopathy and coma may complicate the use of cyclosporin A (CyA). Two patients are described, receiving CyA, who presented with abnormal behaviour, stupor, focal motor activity and were shown to be in complex partial status epilepticus (CPSE). Abnormalities of behaviour and/or stupor in patients receiving CyA may be a manifestation of CPSE. Patients receiving CyA who develop an encephalopathy should have electroencephalography performed at the time of the abnormal behaviour.

Cyclosporin $\mathrm{A}(\mathrm{CyA})$ is an immunosuppressive agent that is effective in the prevention of graft versus host disease and solid organ rejection. Abnormal cerebral function, including seizures, encephalopathy, aphasia and visual disturbance have been described in patients receiving this drug. ${ }^{12}$ Although generalised tonicclonic seizures in patients receiving $\mathrm{CyA}$ have been reported, ${ }^{3-5}$ complex partial status epilepticus (CPSE) has not been described. We present two patients who developed complex partial status epilepticus during treatment with CyA.

\section{Case reports}

\section{Patient 1}

The patient was an 8 year old boy with cystinosis and chronic renal failure. His perinatal and family history were normal. Peritoneal dialysis was started at 8 years of age and 3 months later he received a cadaveric renal transplant. Prophylactic immunosuppression comprised cyclosporin $10 \mathrm{mg} / \mathrm{kg} / \mathrm{day}$, prednisone $2 \mathrm{mg} / \mathrm{kg} /$ day and azathioprine $25 \mathrm{mg}$ daily. Six days following transplantation the patient had an episode of confusion lasting 10 minutes during which the eyes deviated to the right. He became responsive for several minutes and then had tonic eye deviation to the left with clonic movements of the right side of the face which lasted for 5 minutes. Thereafter, he was unresponsive for 10 minutes before returning to normal. He had a blood pressure of 150/ $94 \mathrm{~mm} \mathrm{Hg}$, was alert and answered questions appropriately.

Address for reprint requests: Dr Richard Appleton, Child Health Unit, Princess Mary Maternity Hospital, Great North Road, Newcastle upon Tyne NE2 3BD.

Received 24 January 1989. Accepted 24 February 1989
Apart from extensor plantar responses, neurological examination was normal.

Investigations revealed the following abnormal results: urea $7 \mathrm{mmol} / 1$ (normal $1.5-6.5$ ), phosphate $0.96 \mathrm{mmol} / 1$ (normal $1 \cdot 5-2 \cdot 1$ ), magnesium $0.6 \mathrm{mmol} / 1$ (normal $0 \cdot 8-1 \cdot 2$ ) and albumin $26 \mathrm{~g} / \mathrm{l}$ (normal 35-50). The cyclosporin level was $68 \mathrm{ng} / \mathrm{ml}$ (therapeutic range, $50-400$ ). The haematocrit, platelet count, serum electrolytes, calcium, creatinine, glucose, liver enzymes, and cerebrospinal fluid analysis (protein and glucose levels, cell count, bacterial and fungal cultures) were normal.

He was treated with phenytoin which gave a serum level of $63 \mathrm{mmol} / \mathrm{l}$ (therapeutic range, 40-80) two hours after the infusion. Upon completion of the infusion there was a further episode of eye deviation to the left. He became stuporose, and responded only to painful stimuli. Semipurposeful movements including head-scratching and lip-smacking were observed. An electroencephalogram (EEG), performed at this time, showed runs of almost continuous epileptiform discharges arising from the right hemisphere (fig). These discharges were characterised by sharp and slow wave complexes which were also seen independently at the occipital, posterior temporal and fronto-temporal regions on the right and were frequently interrupted by generalised electro-decremental events. Painful stimuli produced facial grimacing and appropriate limb withdrawal but little response on the EEG. Following intravenous diazepam $(0.4 \mathrm{mg} / \mathrm{kg})$, the epileptiform activity on the EEG disappeared. One hour later, he was alert and able to answer questions appropriately. There was no neurological deficit and the blood pressure was $140 / 90 \mathrm{~mm} \mathrm{Hg}$. The period of stupor lasted 4 hours. Computed tomography of the head, without contrast enhancement, demonstrated prominence of the cortical sulci but no focal abnormalities. A repeat EEG performed five days after the seizure, revealed persistent delta activity in the righ posterior quadrant without epileptiform activity. The patient was treated with magnesium sup- 


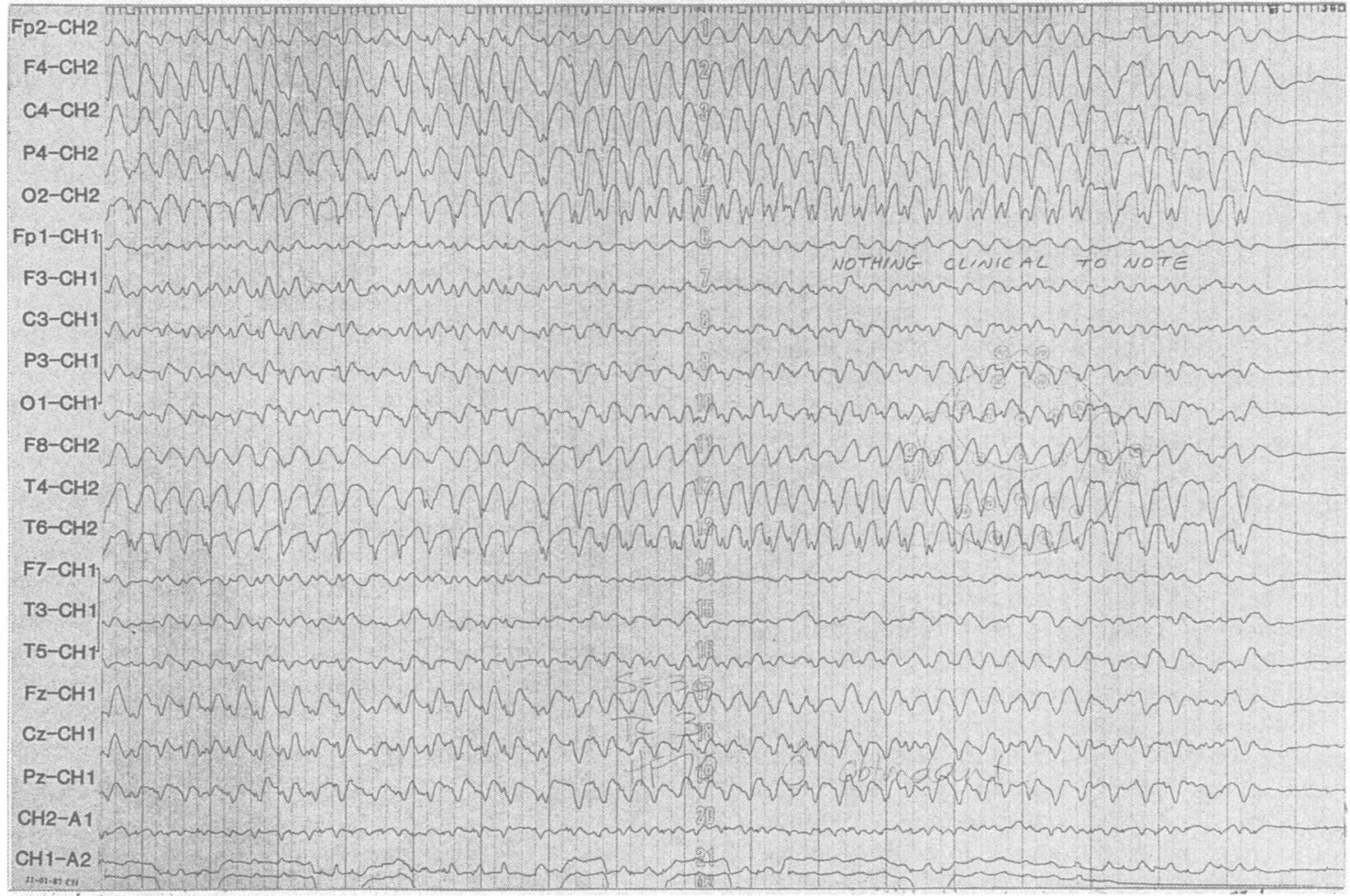

Fig Ictal EEG obtained prior to the injection of diazepam. In the right hemisphere there were continuous runs of sharp and slow waves, interrupted by electro-decremental events (seen at right). Calibration: vertical lines separated by $3 \mathrm{~cm}$; paper speed $30 \mathrm{~cm} / \mathrm{s} ;$ sensitivity $30 \mu \mathrm{V} / \mathrm{mm}$; filter $70 \mathrm{~Hz}$; time constant $0 \cdot 3 \mathrm{~s}$. Ipsilateral cheek reference.

plements, propranolol and valproic acid. The CyA, azathioprine and prednisone were continued at the same dosage. No further seizures occurred and neurological examination was normal when the patient was discharged 21 days later.

\section{Patient 2}

The patient was a 31 year old woman, previously well until she developed acute lymphocytic leukaemia without meningeal involvement. Remission was achieved using prednisone, vincristine and $\mathrm{L}$-asparaginase; craniospinal irradiation was not given. She remained well on maintenance chemotherapy, using oral methotrexate and oral 6-mercaptopurine, for two years, but then suffered a haematological relapse. Remission was achieved successfully and after 6 months she received an allogeneic bone marrow transplant (BMT) and was treated with prednisone $2 \mathrm{mg} / \mathrm{kg} /$ day and cyclosporin A $3 \mathrm{mg} / \mathrm{kg} /$ day. Fifty seven days following BMT the patient developed episodes of confusion, regressive behaviour, and incomprehensible speech. During some of these episodes, her head deviated to the right and horizontal nystagmus was observed. The episodes recurred intermittently over a 2 week period. Most episodes lasted from 3 to 15 minutes. However, two episodes lasted over 30 minutes and stopped only after she had received $2 \mathrm{mg}$ of lorazepam intravenously. Between these episodes, the patient was afebrile and had a blood pressure of
$150 / 90 \mathrm{~mm} \mathrm{Hg}$. She was alert and orientated with a normal mental status. Cranial nerve examination and muscle tone were normal. Deep tendon reflexes were absent at the ankles and diminished elsewhere. The plantar responses were extensor.

The following abnormal laboratory results were obtained: magnesium $0.55 \mathrm{mmol} / 1$ (normal 0.8-1.2), albumin $28 \mathrm{~g} / 1$ (normal 35-50) and aspartate aminotransferase activity (AST) $46 \mathrm{U} / 1$ (normal less than 30). The protein content of the cerebrospinal fluid was elevated to $0.63 \mathrm{~g} / 1$ (normal less than 0.55) but the pressure, cell count, glucose level and cultures (bacterial and fungal) were normal and sterile respectively. The cyclosporin level was $217 \mathrm{ng} / \mathrm{ml}$ (therapeutic range 50-400). The haematocrit, serum electrolytes, calcium, creatinine, urea and glucose were normal. Computed tomography of the head, with contrast enhancement, demonstrated mild cerebral atrophy. An EEG recorded during an episode of abnormal behaviour revealed background slowing with prominent $3.5-5 \mathrm{cps}$ theta activity bifrontally. Frequent bursts of sharp and slow wave activity were seen which were followed by periods of suppression lasting 1-2 seconds. This activity arose independently from the frontal and temporal lobes of each hemisphere but was maximal on the left. Two interictal EEGs were normal.

The CyA and prednisone were continued at the same 
1070

dosage. The patient received magnesium supplements, metoprolol and phenytoin. Within 24 hours of starting phenytoin, the episodes of abnormal movements and behaviour had resolved.

\section{Discussion}

The clinical picture presented by our patients occurred following organ transplantation and the administration of cyclosporin. Although acute encephalopathic episodes may complicate acute rejection crises and infections of the central nervous system consequent to immunosuppression, there was no evidence of either complication in our patients.

There are many reports of neurotoxicity associated with CyA therapy, including encephalopathy, ${ }^{1-6}$ aphasia ${ }^{4}$ visual disturbances, ${ }^{2}$ cerebellar impairment, ${ }^{1-4}$ spinal cord dysfunction ${ }^{1}$ and tonic-clonic seizures. $^{3-5}$ Complex partial seizures have rarely been described. ${ }^{7}$ Although generalised tonic-clonic status epilepticus has occurred in one patient receiving $\mathrm{CyA},{ }^{8}$ complex partial status epilepticus (CPSE) has not been previously reported in such patients.

Both of our patients presented with prolonged episodes of altered behaviour and stupor during which focal motor seizure activity was observed. The episodes of altered consciousness responded to intravenous benzodiazepines. In addition, ictal EEG abnormalities were observed in each patient during the episodes and responded promptly to intravenous diazepam in patient 1. Encephalopathy, abnormal behaviour and visual disturbances have been described both as manifestations of CyA neurotoxicity and of CPSE. ${ }^{29}$ Because it may be difficult to differentiate CPSE clinically from absence status epilepticus, prolonged postictal confusion, various psychiatric syndromes and toxic/metabolic encephalopathies, CPSE is often not recognised. It is therefore possible that the encephalopathy observed in some previous patients treated with CyA may have been CPSE.

CPSE is characterised clinically by a fluctuating and abnormal conscious level that may be accompanied by semipurposeful automatisms. ${ }^{-11}$ The EEG demonstrates typically continuous epileptiform activity which is either focal (usually the temporal lobe) or secondarily generalised from a primary focus. ${ }^{1011}$ Resolution of the epileptiform discharges on the EEG and a return of normal behaviour have been described following the use of intravenous diazepam or phenytoin. $^{910}$ In contrast, EEG in patients receiving CyA who have clinical evidence of neurotoxicity, usually reveals diffuse slowing consistent with a metabolic disturbance. ${ }^{612}$ In the patients described by Rubin ${ }^{2}$ and Lavenstein, ${ }^{6}$ the EEGs revealed spike and wave activity as well as focal slowing. In other reports of CyA-associated encephalopathy, EEG findings were not discussed. ${ }^{1713}$
Appleton, Farrell, Teal, Hashimoto, Wong

Prolonged CPSE may be associated with permanent neurological damage. ${ }^{14}$ Therefore, in patients receiving CyA who develop an encephalopathy, EEG should be performed at the time of the abnormal behaviour. In situations where an EEG is not readily available, intravenous diazepam or phenytoin may be helpful in diagnosis and treatment of CPSE.

The pathogenesis of CyA associated neurotoxicity in our patients is not clear. At the time of CPSE, both patients had hypomagnesaemia, mild hypertension and were receiving corticosteroids. These factors have been implicated previously as a cause of CyA-induced seizures. ${ }^{41516}$ The blood levels of CyA in both patients were within the therapeutic range; metabolites of cyclosporin were not measured. Although the most serious neurotoxicity has been associated with CyA levels above the upper limit of the therapeutic range, ${ }^{258}$ neurological dysfunction has been seen in patients in whom the level of CyA was within the accepted therapeutic range. ${ }^{17}$ However, it is possible that one or more of the metabolites of CyA may be responsible for the neurological toxicity of the drug. ${ }^{18}$

\section{References}

1 Atkinson K, Biggs J, Darveniza P, Boland J, Concannon A, Dodds A. Cyclosporine associated central nervous system toxicity after allogeneic bone marrow transplantation. $N$ Eng J Med 1984;310:527.

2 Rubin AM, Kang H. Cerebral blindness and encephalopathy with cyclosporin A toxicity. Neurology 1987;37:1072-6.

3 Shah D, Rylance PB, Rogerson ME, Bewick M, Parsons V. Generalised epileptic fits in renal transplant recipients given cyclosporin A. Br Med J 1984;289: 1347-8.

4 Thompson CB, June CH, Sullivan KM, Thomas ED. Association between cyclosporin neurotoxicity and hypomagnesaemia. Lancet 1984;ii:1116-20.

5 Beaman M, Parvin S, Veitch PS, Walls J. Convulsions associated with cyclosporin $A$ in renal transplant recipients. Br Med J 1985;290:139-40.

6 Lavenstein BL, Stewart CL. Cyclosporin associated central nervous system toxicity in renal transplant patients (abst). Ann Neurol 1986;20:441.

7 O'Connor JP, Kleinman DS, Kunze HE. Hypomagnesaemia and cyclosporin toxicity. Lancet 1985;i:104-5.

8 Velu T, Debusscher L, Stryckmans PA. Cyclosporinassociated fatal convulsions. Lancet 1985;i:219.

9 Engel J, Ludwig BI, Fetell M. Prolonged partial complex status epilepticus: EEG and behavioural observations. Neurology 1978;28:863-9.

10 McBride MC, Dooling EC, Oppenheimer EY. Complex partial status epilepticus in young children. Ann Neurol 1981;9:526-30.

11 Markand ON, Wheeler GL, Pollack SL. Complex partial status epilepticus (psychomotor status). Neurology 
1978;28:189-96.

12 Wilczek H, Ringden O, Tyden G. Cyclosporineassociated central nervous system toxicity after renal transplantation. Transplantation 1984;39:110.

13 Berden JHM, Hoitsma AJ, Merx JL, Keyser A. Severe central nervous system toxicity associated with cyclosporin. Lancet 1985;i:219-20.

14 Treiman DM, Delgado-Escueta AV. Complex partial status epilepticus. In: Delgado-Escueta AV, Wasterlain CG, Treiman DM, Porter RJ, eds. Advances in Neurology. Vol 34. New York. Raven Press 1983: 69-81.
15 Joss DV, Barrett AJ, Kendra JR, Lucas CF, Desai S. Hypertension and convulsions in children receiving cyclosporin A. Lancet 1982;i:906.

16 Durrant S, Chipping PM, Palmer S, Gordon-Smith EC. Cyclosporin A, methylprednisolone, and convulsions. Lancet 1982;ii:829-30.

17 Polson RJ, Powell-Jackson PR, Williams R. Convulsions associated with cyclosporin $\mathrm{A}$ in transplant recipients. Br Med J 1985;290:1003.

18 Kunzendorf U, Brockmuller J, Jochimsen F, Keller F, Walz G, Offermann G. Cyclosporin metabolites and central nervous system toxicity. Lancet 1988;ii:1223. 